\title{
Economic Consequences of Earthquakes
}

\author{
Dr. A.K. Sinha ${ }^{1}$, Saket Kumar ${ }^{2}$
}

\begin{abstract}
Earthquake is one of the most devastating disasters. A scientific understanding of the event that occurred may make it possible to anticipate future earthquake's consequences, there and elsewhere, so as to cope up with them more effectively. From last few decades, the augmentation of investments in buildings, equipment and infrastructure are mounting at enormous rates. This is making the economic losses of seismic events greater and greater every year, and hence it becomes pertinent to estimate economic loss precisely as its consequences are drastic and long lasting. Estimating the economic loss from the earthquake is also important for devising policies and drawing up requirements for assistance both from within and outside India.

This paper assimilates the investigations of economic losses and makes a comparative study to analyze the variations in the losses during three major earthquakes of India which are Gangtok, Sikkim* Earthquake (18 ${ }^{\text {th }}$ sept2011); Bhuj, Gujarat Earthquake $\left(26^{\text {th }}\right.$ jan2001); and Latur, Maharashtra Earthquake (30 ${ }^{\text {th }}$ sept 1993$)$.
\end{abstract}

Keywords - Earthquake, Economics, Pounding, SAP 2000

\section{INTRODUCTION}

$\mathrm{E}$ XPERIENCES of past and recent earthquake-damages have well established the severity of economic losses and consequences of this event. Earthquakes generate a variety of economic impacts and these impacts adversely affect the economy of the country or state. The economic impact of an earthquake or any natural disaster can be classified as: (i) losses to immovable assets, (ii) losses to movable assets (iii) economic losses due to business interruption, (iv) public sector economic costs, and (v) household income losses due to death, injury, and job disruption[4]. The first impact consists of the direct economic losses due to destroyed or severely damaged buildings and other structures (such as power substations). Losses to movable assets consist of economic losses due to damaged or destroyed contents of buildings and other private property. Public sector economic costs accrue because of loss of revenues and increases in expenses for the public sector. Further, economical losses broadly categorized into direct economical-loss and indirect economical loss. The first two impacts, i.e., losses to immovable assets and losses to movable assets are considered as direct loss and the rest three impacts, i.e., economic losses due to business interruption, public sector economic cost and household income losses are considered as indirect economic loss [9].

A natural disaster like an earthquake has an impact on the Government's revenues. Income loss in the affected region

\footnotetext{
${ }^{1}$ Professor, Department of Civil Engineering, National Institute of Technology, Patna (e-mail : aksinha01@ rediffmail.com)

${ }^{2}$ Student, PG, Structural Engineering, National Institute of Technology, Patna (e-mail : saketkumar0@gmail.com)
}

can lead to a slump in sales and hence, loss of revenue from sales tax, the major source of tax revenue of the Government. But, apart from this direct effect, the total impact on revenues depends on how soon the recovery starts as well as the policy stance of the government. A natural disaster is followed by recovery and reconstruction. While income loss in the region because of the direct impact of the earthquake can lead to a loss of revenues in the short run, the construction boom following the disaster can be a source of additional inflows.

The amount of property loss from a natural disaster depends critically on the development stage of the affected country. To make comparisons across time and space, researchers measure the size of loss relative to the size of the economy (more specifically, as percentage of GDP), rather than the absolute amount in the local currency [5]. It is evident that GDP often drops following a natural disaster, but the size of the loss critically depends on the developmental stage of the economy [1][2]. In cases of Latur earthquake (1993), Bhuj earthquake(2001), Sikkim earthquake(2011) the loss percentage are $0.13 \%, 1.00 \%$ and $0.13 \%$ of GDP of India respectively.

The disaggregation of shaking and secondary effects economic losses for direct losses and total economic losses by 7103 damaging earthquakes from 1 January 1900 to 17 April 2012 in all around the world are shown in Fig. 1 and 2, respevtively. [2]. $30 \%$ of direct economic losses have occurred due to secondary effects of earthquakes and this percentage increases to $38 \%$ for total economic losses, taking into account the indirect losses. This has many implications for our earthquake research.

\section{Direct economic loss}

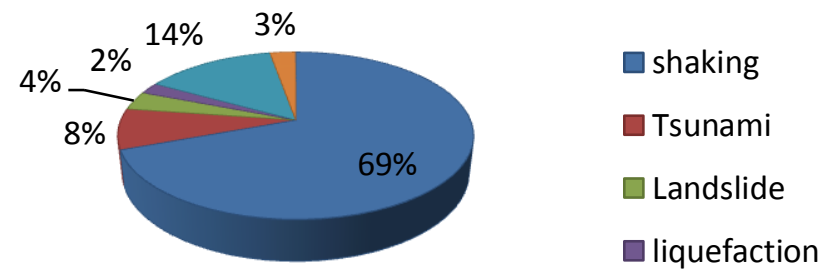

Fig. 1: Disaggregation of shaking and secondary effects economic losses for Direct Economic Losses (After Daniell, E. James., "The CATDAT Damaging Earthquakes Database") 


\section{Total Economical loss}

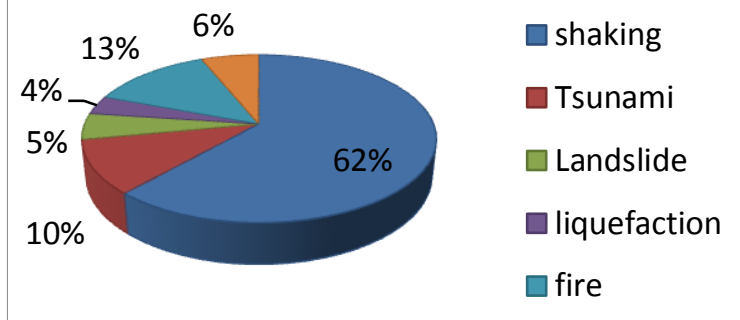

Fig. 2: Disaggregation of shaking and secondary effects economic losses for total economic losses (After Daniell, E. James., "The CATDAT Damaging Earthquakes Database")

\section{Methodology Of The Study}

To make comparisons across space and time the economic losses are measured relative to the size of the economy more specifically, as percentage of GDP. All the raw data regarding the events are referred from assessment reports of World Bank and Asian development bank. White papers issued on the event by respective state governments are also used for preparing database. All the economic losses are used in terms of USD\$ for calculation of percentage of GDP.

\section{The CAse Of The 1993 Latur EarthquaKe}

A series of earthquakes of magnitude of about of 6.4 on the Richter scale struck the southeastern region of Maharashtra at 3.56 AM on September 30, 1993. The epicenter was near the village of Killari located in the Latur district, about 300 miles south east of Mumbai.

Topography and soil condition: Latur is situated $636 \mathrm{~m}$ above mean sea level, on the Balaghat plateau, on the MaharashtraKarnataka state boundary. This area of Maharashtra has extremely hot weather and an acute water scarcity. The soil is comprised of expansive clayey soils (black cotton soil) up to seven feet thick in places.

The Earthquake: This was a rare intraplate earthquake in the centre of the sub-Indian continent on the Deccan Plateau. There is no historic record of earthquakes in the area and it is the lower bound of water depths of reservoirs where induced seismicity has been documented.

The devastating effects of the earthquake were largely due to a vulnerable housing stock, the shallow focus of the earthquake, which caused widespread damage, the time of the event (early morning when many people were asleep in vulnerable structures), and the density of the population in the area. Based on historical records, Marathwada was considered an area of low seismicity; therefore no special seismic design provisions were required for residential buildings.

Damage: The earthquake severely affected 67 villages in the districts of Latur and Osmanabad where about 8,000 people were killed and 16,000 were injured. Considerable damage also took place in 11 other districts including Satara. In total, approximately 225,000 houses were destroyed or damaged, and more than 58,000 families were left homeless. The total loss of public and private property was estimated 364 million USD.

Earthquake rehabilitation project: Soon after the earthquake, the Government of Maharashtra launched a massive rehabilitation project to cover the entire earthquake-affected area. The reconstruction project was officially titled the Maharashtra Emergency Rehabilitation Project (MERP). This was one of the largest rebuilding projects in the world with objectives of enhancing the earthquake resistance of buildings, and reinforcing the capability of the government to respond more efficiently to possible future disasters.

\section{The Case Of The 2001 Bhuj Earthquake}

The earthquake: The 2001 Gujarat earthquake occurred on 26 January, India's 52 ${ }^{\text {nd }}$ Republic Day, at 08:46 AM IST and lasted over 2 minutes. The epicenter was about $9 \mathrm{~km}$ southsouthwest of the village of Chobri in Bhachau Taluka of Kutch District. The earthquake killed around 20,000 people, injured another 167,000 and destroyed nearly 400,000 homes.

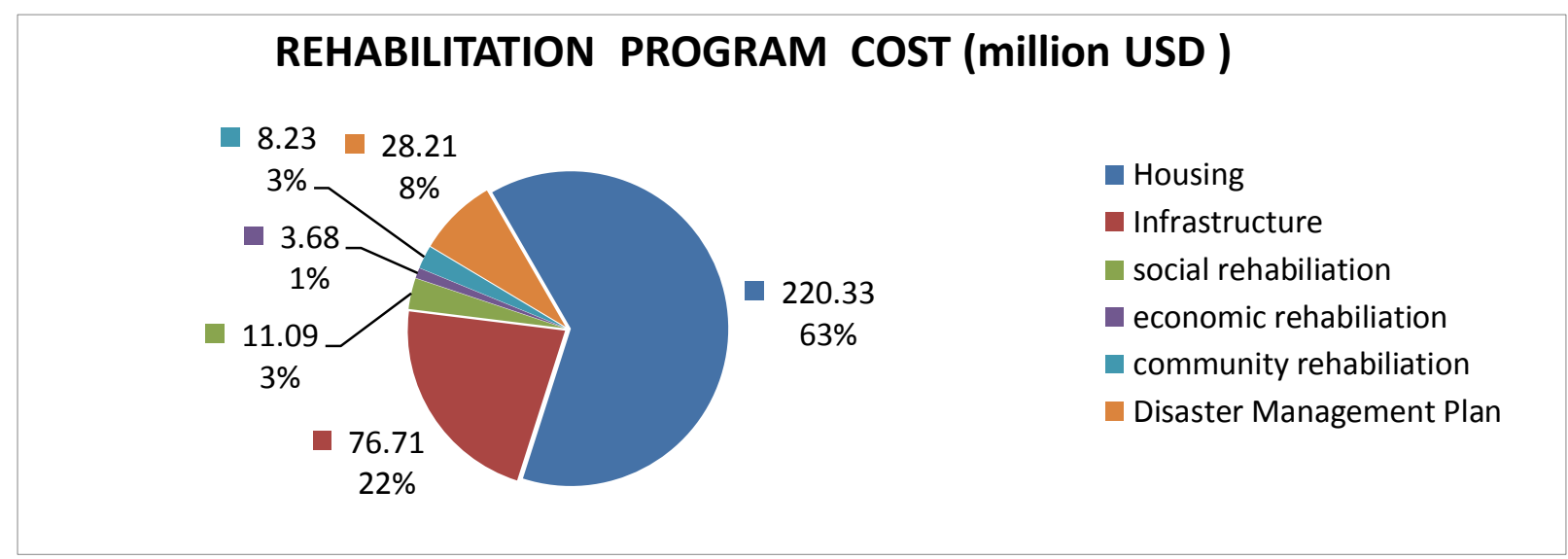

Fig. 3: Sectoral rehabilitation cost for Latur earthquake possible that this event may have been induced by the nearby Lower Tirna Reservoir, although the depth of its waters is on
Topography: In terms of topography, Gujarat shows a wide variation. The topography of Gujarat is divided into 3 major 
regions, namely: (i)The Peninsular - the region, which is also known as Saurashtra, is essentially a hilly tract. (ii) The Kutch - It is a barren and rocky area containing the great Rann. The Rann is further Kutch and the Aravalli hills to the river Damanganga.

Damage: The scale of physical destruction was also immense: 1.2 million homes, 2,000 health facilities, 12,000 schools, hundreds of public and other buildings (including thousands of records), dams, water supply systems, roads, power and telecommunications systems, factories, cottage industries and farms were all destroyed or damaged, effectively crippling the state's social, public, and municipal services as well as its economy. The earthquake affected 12 districts but Kutchh, one of the poorest districts in the state, was most seriously affected with an average of $70 \%$ of all buildings destroyed.

Economical-impact: The total loss of public and private property was estimated 4.97 billion USD according to World Bank and the percentage loss in terms of GDP was $1 \%$ of GDP of India. The earthquake adversely affected medium- and small-scale industries in the quake affected region on large scale, and that had resulted in loss of employment for thousands of people (around 488 thousand persons).

As previously stated that the quake also affects the revenue of the state, revenue loss in April 2011 was estimated as 40 per cent of the expected revenue for the entire state except the Bhuj circle. For Bhuj, the revenue loss was taken to be 80 per cent for the whole of 2001-2002.

Earthquake rehabilitation program: Rehabilitation and reconstruction program in the earthquake affected areas including restoration of houses, public buildings and basic infrastructure in the roads and irrigation sectors is detailed in Figure 04.

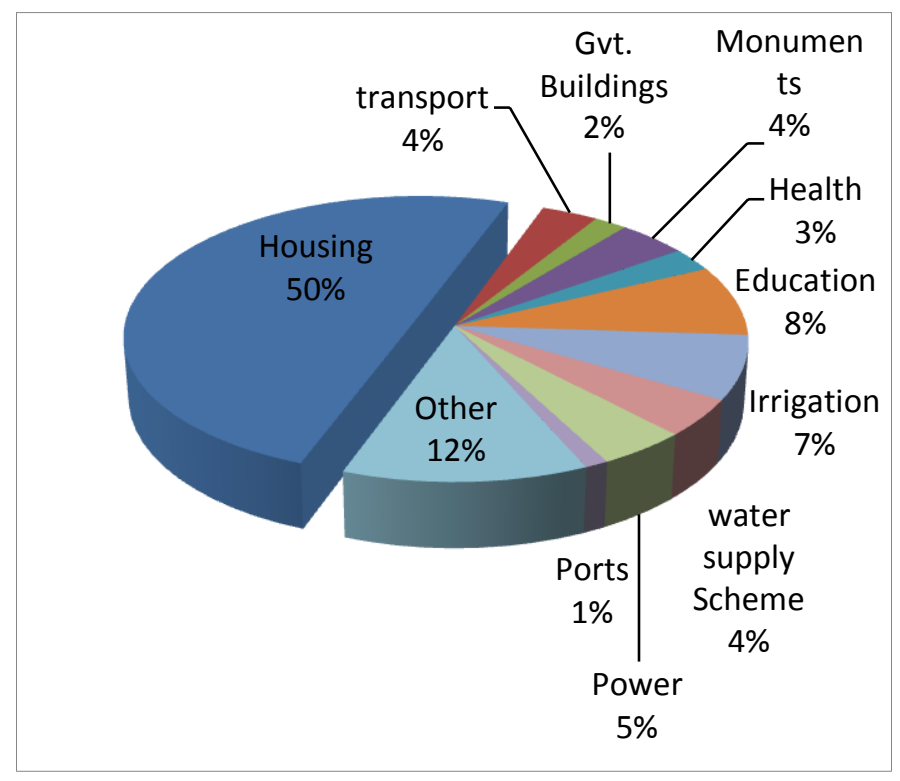

Fig. 4: Sectoral rehabilitation cost (in \%) for Bhuj earthquake, 2001.

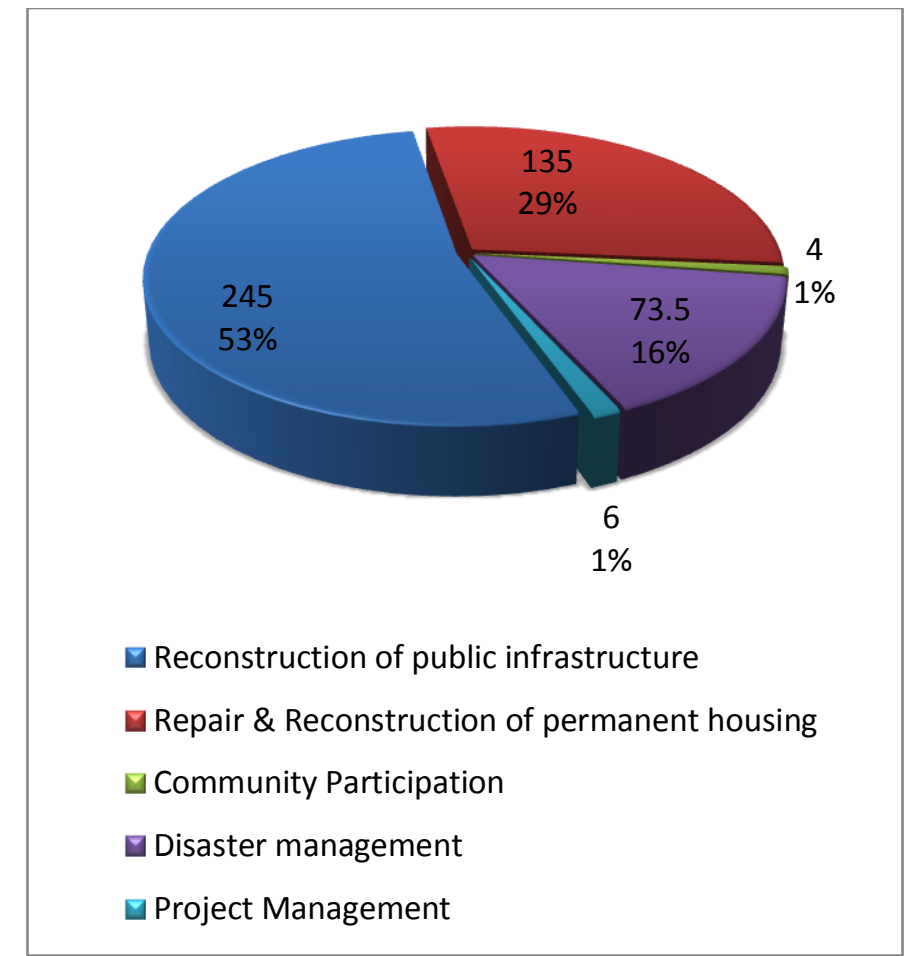

Fig. 5: Disaggregated rehabilitation cost (in million USD) for Bhuj earthquake, 2001.

\section{The CASE OF The 2011 SIKKIM EARTHQUAKE}

The M6.9 earthquake hit Sikkim on 18th September 2011 with its epicenter located at $27.72^{\circ} \mathrm{N}, 88.06^{\circ} \mathrm{E}$, near IndiaNepal border, about $68 \mathrm{~km} \mathrm{NW}$ of Gangtok and at a focal depth of $19.7 \mathrm{~km}$ as reported by USGS. Maximum observed shaking intensity during this earthquake was VIII on MSK scale. About 100 deaths are reported in India with the maximum of at least 60 in the state of Sikkim and total loss of property was about 2.26 billion USD.

Topography: Sikkim has very complex topography. It has 28 mountain peaks, more than 80 glaciers, 27 high altitude lakes, five major hot springs and more than 100 rivers and streams. The State has not only been endowed with a peculiar topography but it is ecologically sensitive and prone to earthquakes. It has fragile ecology being the steepest and the highest State in the country, and the third highest landscape on the globe. It is a mountainous State crisscrossed by narrow valleys and steep cliffs. The young fold mountains are characterized by a weak geology, comprising sedimentary and low grade metamorphic rocks which are susceptible to weathering and erosion.

It is worthwhile to mention here that Sikkim and adjoining regions are known to be part of the seismically active region of the 'Alpine-Himalayan global seismic belt', with four great earthquakes of the world of magnitude 8.0 and above occurring in this region.

The Earthquake: As previously mentioned, the earthquake caused severe damages to life and property throughout the State. The high density tremor triggered other natural calamities in the form of landslides, road blocks, falling boulders, lake bursts, flash floods etc. After the tremor, incessant heavy rain also continued for more than a week. This 
caused extensive damage to human life, property and infrastructure.

Losses and Damages:Human life: 63 human lives lost. Many people lost their limbs and eyes, 597 people were injured and hospitalized with grievous injuries.

Social infrastructure: Total schools damaged: 759 nos., Hospitals / PHCs damaged: 377 nos.; ICDS (Anganwadi) damaged: 875 nos.; Other Government Buildings damaged: 1255 nos.

Transportation infrastructure: Total Roads damaged: 3230 $\mathrm{km}$; Village footpaths (cement concrete) damaged: 1596 nos.; Bridges / Culverts damaged: 8135 nos.

Energy infrastructure: Power infrastructure: Major damage to generation plants, electrical grid, substations, transformers and local distribution network

Water management infrastructure: Water supply schemes damaged: 1529 nos.; Minor Irrigation works damaged: 204 nos.; Flood Control Management works damaged: 533 nos.

Community infrastructure: Gram Panchayats offices damaged: 60 nos.; Community toilets damaged: 155 nos. ; Village level cooperatives (MPCS) damaged: 49 nos. Rural Product Marketing Centers (RPMC) damaged: 8 nos.

Cultural heritage institutions: Damage to 259 nos. of religious institutions, monuments and various heritage monasteries, temples and churches. Along with this valuable artifacts have also been destroyed which also included historic manuscripts.

Earthquake rehabilitation program: Rehabilitation and reconstruction program cost in the earthquake affected areas including restoration of houses, public buildings and basic infrastructure in the roads and irrigation sectors has been shown in pi-chart as following.

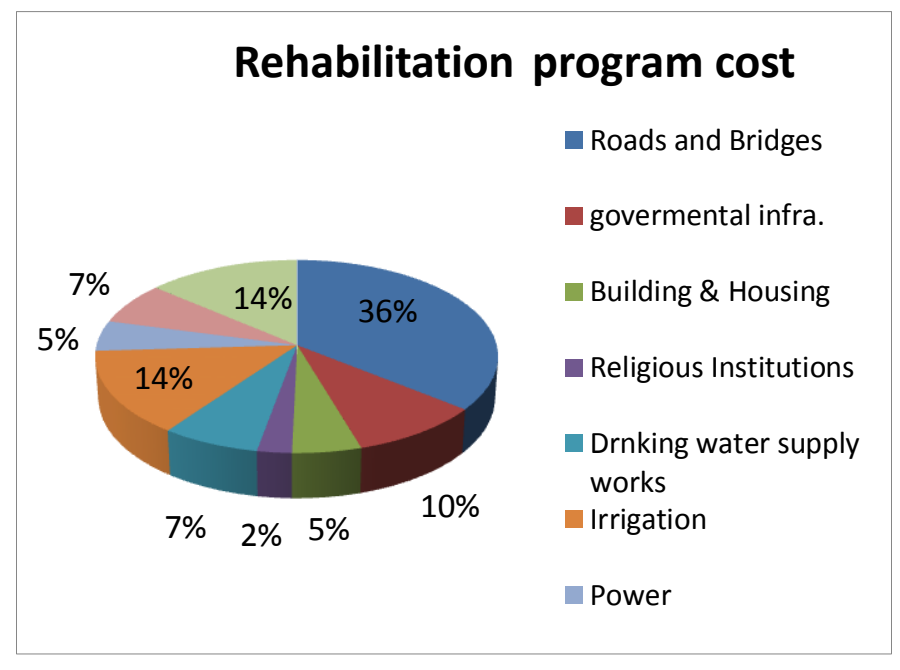

Fig. 6: Sector wise earthquake rehabilitation program cost (in \%) for Sikkim earthquake, 2011

\section{Comparative Results}

Among three earthquakes of Latur (1993), Bhuj(2001), Sikkim(2011), Bhuj has the highest percentage loss which is $1 \%$ of total GDP of India. Given that Gujarat accounts for only about 7 percent of the GDP of India the impact of the quake on the GDP of the country was insignificant and that can be analysed in figure 1. The same thing is valid for other two earthquakes with $0.128 \%$ loss of NGDP for Latur earthquake and $0.132 \%$ loss of NGDP for Sikkim earthquake.

While the impact of the earthquake on India's gross domestic product is insignificant, but absolute loss was very high and, in the areas where it struck, the earthquake devastated lives, social infrastructure, and economic foundations.

With time the percentage of indirect economic rehabilitation cost tends to increase as compare to direct economic cost. In last three decade the \% cost of Housing \& Building sector has decreased and there is an evident increment can be seen in sectors like irrigation, Water supply, power and education. Here it is worthwhile to mention that in Sikkim earthquake the sector of roads \& bridges has the heaviest weightage among other sectors due to the rough terrain and complex topography of the state.

TABLE I

COMPARISON OF ECONOMICAL LOSSES IN \% OF GDP OF INDIA.

\begin{tabular}{|l|l|l|l|l|l|}
\hline S.No & Event & $\begin{array}{c}\text { Absolute } \\
\text { Loss } \\
\text { (million } \\
\text { USD) }\end{array}$ & $\begin{array}{c}\text { GDP of } \\
\text { India } \\
\text { (billion } \\
\text { USD) }\end{array}$ & $\begin{array}{c}\% \\
\text { Contributi } \\
\text { on of state } \\
\text { in NGDP* }\end{array}$ & $\begin{array}{l}\% \text { loss of } \\
\text { GDP of } \\
\text { India }\end{array}$ \\
\hline $\mathbf{1}$ & $\begin{array}{l}\text { Latur } \\
(1993)\end{array}$ & 364 & 284.2 & 16.5 & 0.128 \\
\hline $\mathbf{2}$ & $\begin{array}{l}\text { Bhuj } \\
(2001)\end{array}$ & 4970 & 494 & 8.1 & 1.00 \\
\hline $\mathbf{3}$ & $\begin{array}{l}\text { Sikkim( } \\
\text { 2011) }\end{array}$ & 2260 & 1708.5 & 0.08 & 0.132 \\
\hline
\end{tabular}

\section{CONCLUSION}

The damage is primarily attributed to poor design and construction practices and lack of quality control. Poor construction practices prevalent in the area spell tremendous risk for the population of this region.

While absolute economic losses are very high for the mentioned earthquakes, but their percent loss in terms of GDP of India is insignificant. In planer areas it might be suggested that the main economic losses occur due to collapse of buildings which is further reflected in the rehabilitation program cost of housing sector for Latur earthquake (1993) and Bhuj earthquake (2001). On contrary, in hilly area having rough topography like Sikkim, the main economic loss was due to infrastructural-damage which is well reflected in rehabilitation program for Sikkim earthquake (2011).

In planer areas, indirect economic losses are more as compare to rough topography or hilly areas. Higher population density which leads to higher industrial and commercial density in planer areas might be a main factor for this higher indirect economic loss in the area. 
Overall, the solution lies in opting for safer construction through choice of appropriate construction systems in corporation with earthquake resistant technology, use of good construction materials and their quality control, and involvement of competent manpower for design construction and supervision.

\section{REFERENCES}

[1] Daniell ,J.E., Vervaeck ,A., “ The worldwide economic impact of historic earthquakes”; 15WCEE LISBOA 2012, page 6-7.

[2] Daniell, E. James., "The CATDAT Damaging Earthquakes Database", Australian Earthquake Engineering Society 2010 Conference, Perth, Western Australia,

[3] Document of The World Bank, "Maharashtra Emergency Earthquake Rehabilitation Project", Report No. 19218

[4] Gokhale, Vasudha A., Joshi, R Deepa., Abhayankar, A.L., "The Psychological And Socio Economic Aspects Of Earthquake Occurrence", 13 WCEE, CANADA 2004.

[5] Gujarat Earthquake Recovery Program, Assessment Report by the World Bank and the Asian Development Bank, March, 2001. Page: 11-13.

[6] Government of Sikkim, Land Revenue and Disaster Management Department "White Paper on The High Intensity Earthquake $18^{\text {th }}$ September 2011 in Sikkim", December 2012

[7] Lahiri, Ashok K., Sen, Tapas K., Rao, Kavita R., Jena, Pratap R., "Economic Consequences of the Gujarat Earthquake", pp:9-12.

[8] Majorie, G., Chandra, Krimgold, F., Pantelic, J., "Overview of the Maharashtra, India Emergency Earthquake Rehabilitation Program", 12WCEE 2000.

[9] Rai, C. Durgesh, Mondal Goutam, Singha, Vaibhav; Tripti Pradhan, "2011 Sikkim Earthquake Effects on Built Environment \& Perspective on Growing Seismic Risk", National Information Center on Earthquake Engineering. 